\title{
EDITORIAL
}

\section{BEFORE AND AFTER THE NETWORK}

\section{Christian Ulrik Andersen \& Geoff Cox}

APRJA Volume 9, Issue 1, 2020

ISSN 2245-7755

CC license: 'Attribution-NonCommercial-ShareAlike'. 
How do we think about networks under postdigital conditions? What does this imply for research?

This journal issue takes as its outset, the call of the transmediale festival to "[leave] behind a decade marked by a backlash against the Internet and the network society" in order to re-evaluate the limits of 'networks'. It refers to Robert Filliou's "The Eternal Network," an idealistic notion from the 1960s, pointing to the interconnectedness of everyday-life actions across an emerging global world at that time. This is a good reminder that network cultures exist beyond the technical reality of network culture as we now know it despite our primary identification of networks with social media and planetary computation. By drawing on the legacies of critical and autonomous network cultures, the aim was to make the limits of Internet-based networks visible but also highlight alternatives. Is there a conceivable counter-power to networks? Which alternative technological models and cultural narratives are needed to construct the principles of end-to-end communication anew? How might the critique of networks extend to non-western contexts and reflect the limits in a global perspective?

\section{The periodizing logic of networks}

To answer such complex questions, it may be useful to reflect on the periodizing logic that invites us to leave behind "the backlash against the Internet." What comes before and after the network?

The German media theorist Harmut Winkler has proposed that, in a historical perspective, the discourse around "new media" repeatedly emphasize the "antihierachical character of the new medium": an utopia where social mediation is suspended.
Winkler, writing in 1997, quotes Tim BernersLee for saying "There will be an explosion; more and more people will write about themselves". The World Wide Web, in other words, came with a dream of a future that extends our social life into a universe where everyone becomes equal in the sense that every point in the network is equally far away (or close) to everyone, everyone author is equal, and everyone has the right to speak (unlike censored mass media): "Consensusbuilding appears to be superfluous, and it seems that the hierarchizing social machine has lost its power." (213-214)

The networked computer as a "social structure in a 1:1 map" and a "pure extension" of social interaction parallels a more general historical ideal of technical images. The construction of technical images has always claimed to come as a 1:1 reality without language, social conventions and compression: a "liberated [...] universe through which hope passes." In this sense, the utopia of networked media is yet another example of how technological media "chose the escape to iconicity;" or, media without representation (ibid). It is a discourse that fails to acknowledge both that signification is arbitrary and messy (mediated by someone, something, somewhere), and that the process of 'standardization' (that ignores the arbitrariness of media) is a recurring cultural figure: every (Western) social structure has always attempted to place its own iconic media in the universe. What other beginnings and ends of networks might there be?

\section{Messy networks that fall apart}

Networks are everywhere - intrinsic to all (de)centralized human and non-human 'business' and communication. However, the 
once canonical model of centralized, decentralized and distributed networks is in need of differentiation and more detail today (as a cultural form as well as a socio-technical reality). This means broadening the discussion of networks to other ecologies that would include non-human elements such as animals, energy, clouds, climate, and so on. A key reference here might be Anna Lowenhaupt Tsing's work on matsutake mushrooms and global supply chains that define messy networks of ruin and regrowth, with people very much entangled with nonhuman entities. In a world increasingly defined by capitalist ecological devastation (and the spread of infectious disease, as we write), Tsing asks "What do you do when your world starts to fall apart? I go for a walk, and if I'm lucky, I find mushrooms." (1) Her argument is that it's not productive to dwell on destruction no matter how bleak the scenario may seem, as this perpetuates the same logic that produced it in the first place, but instead look to resilient life-forms that can suggest ways of surviving precarity and the messes we have created for ourselves. Even in the ruins we can find hopeful descriptions of supply chains that use networks productively to thrive as part of broader eco-systems, and that stress "ephemeral assemblages and multidirectional histories." (61)

There is a strong sense that despite this ever-lasting debate over networks and their potential to rethink eco-socio-technical structures, relatively little of this network thinking has permeated the artworld or research cultures in other than straightforward ways. The articles presented in this journal issue take up the invitation to explore this line of thinking and ask what it means to research networks, and more-over to think beyond the organizational logic of the academy to other forms of organizing knowledge production and distribution.[1] What are the limits of research networks and what would an end-to-end principle of research look like?

In each their own way the authors of this journal issue deconstruct the really existing and imaginary network; they highlight its cultural, political, ecological, geopolitical and colonial implications seen from diverse and local cultural contexts as well as the perspective of a globalization, and through various cultural and artistic practice they invite the reader to contemplate this beginnings and ends of networks.

Aarhus/London, July 2020

The publication of this journal follows a mail list discussion and workshop hosted by The Marshall McLuhan Salon at the Canadian Embassy in Berlin, in January 2020, organized by Digital Aesthetics Research Center (DARC) at Aarhus University, transmediale festival, Centre for the Study of The Networked Image at London South Bank University, and Global Emergent Media Lab (GEM-lab) at Concordia University. With additional thanks to Clemens Apprich, Joshua Neves, Søren Pold, Winnie Soon, and Magda Tyżlik-Carver.

\section{Notes}

[1] A raw and messy unedited version of the mail list exchange can be downloaded from https://transmediale.de/content/ research-networks-1. 


\section{Works cited}

"Robert Filliou defines the Eternal Network."

Youtube. https://www.youtube.com/

watch?v=9BgOfsG7J0Q. Accessed June

23, 2020.

"transmediale 2020 - End to End." trans-

mediale - art \& digital culture. https://2020.

transmediale.de/festival-2020. Accessed

June 23, 2020.

Tsing, Anna Lowenhaupt. The Mushroom at the End of the World: On the Possibility of Life in Capitalist Ruins. Princeton University Press, 2015.

Winkler, Hartmut. Docuverse - Zur

Medientheorie der Computer. Boer, 1997. 